\title{
Establishing an association between molecular markers and sheath blight (Rhizoctonia solani Kuhn) resistance in rice
}

\author{
Megha Joshi ${ }^{1}$, Pawan K. Singh ${ }^{1 *}$, Showkat A. Waza ${ }^{1}$, Vineeta Singh ${ }^{2}$, Sanjay Goswami ${ }^{2}$, Pallavi ${ }^{3}$, Sujit \\ Kumar $^{4}$, Anil K. Singh ${ }^{1}$, Najam W. Zaidi ${ }^{5}$ and Uma S. Singh ${ }^{5}$ \\ ${ }^{1}$ Department of Genetics and Plant Breeding, Institute of Agricultural Sciences, Banaras Hindu University, \\ Varanasi- 221005, India \\ ${ }^{2}$ Department of Mycology and Plant Pathology, Institute of Agricultural Sciences, Banaras Hindu University, \\ Varanasi- 221005, India \\ ${ }^{3}$ Department of Botany, Faculty of Science, Banaras Hindu University, Varanasi- 221005, India \\ ${ }^{4}$ Uttar Pradesh Research Council, Lucknow (UP), India \\ ${ }^{5}$ IRRI-STRASA India Office, $9^{\text {th }}$ Floor Agrawal Corporate Tower, Plot No. 23, Rajendra Place, New Delhi, 110 \\ 012, India
}

*Corresponding author: pksbhu@gmail.com

\begin{abstract}
The use of multiple regression analysis to validate molecular markers associated with sheath blight resistance was carried out in 73 germplasm accessions of rice. Data on disease reaction was recorded as lesion size and used for calculation of AUDPC (Area Under Disease Progress Curve) and Percent Disease Index (PDI). A variation in AUDPC ranging from 217.78 to 793.33 with a mean value of 532.51 was recorded for the genotypes infected with sclerotia. PDI ranged from 28.89 to 84.44 with the mean values of 55.40 for infected lines. The AUDPC and PDI values for resistant check Tetep were found to be 432.70 and 45.22 , respectively. Higher AUDPC and PDI values serve as an indication for susceptibility towards the disease reaction. The PIC value for the SSR loci varied from 0.225 to 0.743 with an average value of 0.47 . Markers RM336, RM209, RM251 and RM224 were most informative on the basis of their high PIC values. UPGMA clustering based on molecular data and AUDPC were found to be in good agreement with each other. Twenty five germplasm accessions were grouped as common in cluster I of dendrogram generated by all alleles, cluster I of dendrogram constructed by Tetep specific alleles, and clusters I and II of the AUDPC dendrogram. Multiple regression analysis revealed that the two markers RM251 175 and RM257 150 may be considered as markers for association with low disease index (resistance to sheath blight) in rice. Amongst the germplasm accessions, IC383396 and IC426017 behaved as potentially resistant to sheath blight.
\end{abstract}

Keywords: germplasm accessions, multiple regression analysis (MRA), rice, sheath blight resistance, SSR markers.

Abbreviations: AUDPC_Area under disease progress curve, PDI_Percent disease index, MRA_Multiple regression analysis, PIC_Polymorphic information content, UPGMA_Unweighted pair group method with arithmetic mean.

\section{Introduction}

Sheath blight is one of the most devastating diseases causing huge damage to rice yield and quality globally every year. During favorable conditions this disease may cause yield reduction of up to $50 \%$ in major rice growing areas (Zheng et al., 2013). Losses depend on the growth stage of plant at which infection occurs, level of resistance in a particular genotype and prevailing environmental conditions. Sheath blight (SB) is caused by a semi-saprophytic soil-borne fungal pathogen, Rhizoctonia solani Kuhn having wide host range. The fungus survives either as sclerotia or mycelia in plant debris. The sclerotia float to the surface of flooded water in rice fields and germinate on plant sheaths forming appressoria for infection. Initial symptoms of sheath blight appear in the form of circular, oblong or ellipsoid, greenish grey, water soaked spots of about $1 \mathrm{~cm}$ long that occur on leaf sheaths near the water line. After the initial infection, the pathogen moves on the plant through surface hyphae and develops new infection structures over the entire plant, causing significant necrotic damage (Ou, 1985). Sheath blight (SB) disease is prevalent in almost all major rice growing areas of the world i.e., Bangladesh, China, Columbia, Cube, Germany, India, Indonesia, Iran, Japan, Korea, Malaysia, Moscow, Netherlands, Nigeria, Philippines, Senegal, Srilanka, Raiwan, Thailand, Trinidad, Tobago, U.K., U.S. and Vietnam (Dasgupta, 1992).

The immunities in rice germplasm have not been found so far, but moderate or partial resistance is available against the sheath blight pathogen (Liu et al., 2009). Some of the rice lines such as Tetep, Tadukan, Teqing, Jasmine 85, ZYQ8, Minghui 63, LSBR-5 and LSBR-33 have been found to show relatively high degree of quantitative resistance against this pathogen under field conditions (Li et al., 1995 and Pan et al., 1999). Rice sheath blight resistance has been reported to be a typical polygenic quantitative trait (Pinson et al., 2005 and Jia et al., 2009) and around 50 SB resistance quantitative trait loci (SBR QTLs) have been detected on all the 12 chromosomes of various rice species (Xu et al., 2011 and Wang et al., 2012). The spotting of molecular markers linked 
with rice SB resistance can be used in breeding programs pertaining to incorporation of resistance toward this pathogen. Detection of molecular markers associated with various QTLs is the first step in marker assisted breeding (Misztal, 2006). Rice double haploid lines and RILs have been extensively used for QTL mapping for sheath blight resistance (Kunihiro et al., 2002; Han et al., 2002). However, the non-availability of mapping populations and substantial time needed to develop such populations are the major limitations in identification of molecular markers for specific traits. To overcome these limitations, the identification of molecular markers associated with trait of interest through multiple regression analysis, involving the use of diverse germplasm collections have so far been adopted in many crop species (Maureira-Butler et al., 2007; Dholakia et al., 2008; Ruan et al., 2009). These include RAPD markers associated with various polygenic traits in Asian rice (Virk et al., 1996) and protein content in wheat (Dholakia et al., 2001), SCAR markers associated with birch fiber length trait (Wang et al., 2008), ISSR markers associated with various yield traits (Vijayan et al., 2006) and protein content (Kar et al., 2008) in mulberry, and microsatellite markers associated with seed size in soybean (Hoeck et al., 2003) and mite resistance in coconut (Shalini et al., 2007). The present study involves an evaluation of genetic diversity and use of multiple regression analysis to validate the molecular markers associated with sheath blight resistance in rice.

\section{Results}

\section{AUDPC and PDI of the lines infected with sclerotia}

Data on disease reaction was recorded as lesion size and used for calculation of AUDPC and PDI (Table 1). A variation in AUDPC ranging from 217.78 to 793.33 with a mean value of 532.51 was recorded for lines infected with sclerotia. The genotype IC281785 exhibited highest area under disease progress curve, while the lowest mean value was exhibited by genotype IC346004. The lines with higher AUDPC were more susceptible to sheath blight than the lines with lower AUDPC values. The resistant check Tetep had an AUDPC value of 432.70 . PDI values ranged from 28.89 to 84.44 with the mean values of 55.40 for infected lines. The genotype IC282815 exhibited highest (84.44) and IC346004 the lowest (28.89) PDI value. PDI for resistant check Tetep was found to be 45.22 .

\section{Genetic diversity based on AUDPC}

The taxonomic distance matrix for 73 genotypes was employed for cluster analysis using UPGMA method and the dendrogram was constructed based on Jacquard's similarity coefficients of AUDPC (Fig 1). In the dendogram, the genotypes were grouped into four main clusters viz., Cluster I, II, III and IV consisting of 23, 27, 19 and 4 genotypes, respectively. Cluster I was subdivided into two main sub clusters Ia and IIb consisting of eleven and twelve genotypes, respectively. The major cluster, cluster II was subdivided into two sub clusters IIa (5 genotypes) and IIb (22 genotypes). Cluster III was subdivided into two main sub clusters namely IIIa (15 genotypes) and IIIb (4 genotypes). Cluster IV was not further subdivided.

\section{SSR polymorphism and marker efficiency}

Out of 16 primers used, 13 produced reproducible and polymorphic banding pattern, while three primers (sbq1,
RM5481 and RM338) were found to be monomorphic (Table 2 ). The thirteen polymorphic primers produced a total of 34 fragments, the size of whom varied from 100bp (marker K39512) to 220bp (marker RM536). Maximum number of fragments was produced by primers RM336 and RM210, yielding four fragments each. An average of 2.6 fragments per primer was produced by primers showing polymorphic amplification. Gel images showing SSR banding profile obtained by primer RM224 are presented in Fig 2. The PIC value of SSR markers in the present study ranged from 0.225 to 0.743 with an average PIC of 0.47 . Markers RM336, RM209, RM251, and RM224 were most informative on the basis of high PIC value of $0.743,0.694,0.668$ and 0.656 , respectively. SSR marker K39512 showed least PIC value of 0.225 .

\section{Genetic diversity based on all the alleles amplified by SSR} markers

A UPGMA cluster diagram obtained by all the 34 alleles (amplification products) generated by 13 polymorphic SSR markers grouped the 73 rice genotypes into eight major clusters (Fig 3). Cluster I, consisted of 38 genotypes which were again subdivided into two sub clusters, viz., Ia (14 genotypes) and $\mathrm{Ib}$ (24 genotypes). Tetep was allocated under sub cluster Ia. Cluster II includes only 3 genotypes. Cluster III contained twelve genotypes which were further divided into two sub clusters IIIa (6 genotypes) and IIIb (6 genotypes). Two genotypes were present in Cluster IV and six in Cluster V. Clusters VI and VII consisted of five and six genotypes, respectively. The cluster VIII was monogenic containing only one genotype.

\section{Validation of SSR markers for Tetep specific alleles}

Marker RM306, flanking the sheath blight resistant QTL $q S B R 1-1$, amplified a fragment of $165 \mathrm{bp}$ in Tetep and 47 other genotypes. RM251 linked to QTL qSBR3-1 produced an amplification product of $175 \mathrm{bp}$ in 20 genotypes including Tetep. SSR markers RM3691 and RM336 flanking the QTL $q S B R 7-1$, produced the Tetep specific bands of $160 \mathrm{bp}$ and 175 bp in 60 and 23 genotypes, respectively. Similarly, marker RM210 associated with QTL $q S B R 8-1$ produced a fragment of $210 \mathrm{bp}$ in Tetep and other 29 genotypes. RM257 (qSBR9-1) amplified a band of $160 \mathrm{bp}$ in 61 genotypes including Tetep. SSR markers sbq11 and RM224 flanking a major QTL qSBR11-1, amplified respective fragments of 160 and $140 \mathrm{bp}$ in Tetep. Similarly, RM3428 and RM209 flanking the QTL $q S B R 11-2$ amplified 140 and $125 \mathrm{bp}$ fragments in 62 and 30 genotypes, respectively. SSR markers RM536 and RM202 flanking the major QTL qSBR11-3 produced the Tetep specific amplification products of 220 and 180 bp in 58 and 53 genotypes, respectively. Marker K39512 revealed the amplified fragment size of $100 \mathrm{pb}$ in Tetep and 63 other genotypes.

\section{Genetic diversity based on Tetep specific alleles}

Based on the binary data generated by either presence or absence of an amplification fragment specific to resistant check Tetep, the cluster analysis was carried out for all the rice genotypes (Fig 4). In cluster analysis, the genotypes were grouped broadly into seven clusters, viz., Cluster I, II, III, IV, V, VI and VII. The major cluster i.e., cluster I consisted of 42 genotypes, which were further divided into five sub clusters, viz., Ia (10 genotypes), Ib (4 genotypes), Ic (14 genotypes), Id (5 genotypes) and Ie (9 genotypes). The check (Tetep) was 
Table 1. Performance of rice germplasm accessions including check (Tetep) for sheath blight resistance.

\begin{tabular}{lccccc}
\hline Parameter & Min. & Max. & Mean & SE $( \pm)$ & Resistant check Tetep \\
\hline AUDPC & 217.78 & 793.33 & 530.35 & 13.38 & 432.70 \\
PDI & 28.89 & 84.44 & 55.32 & 1.40 & 45.22 \\
\hline
\end{tabular}

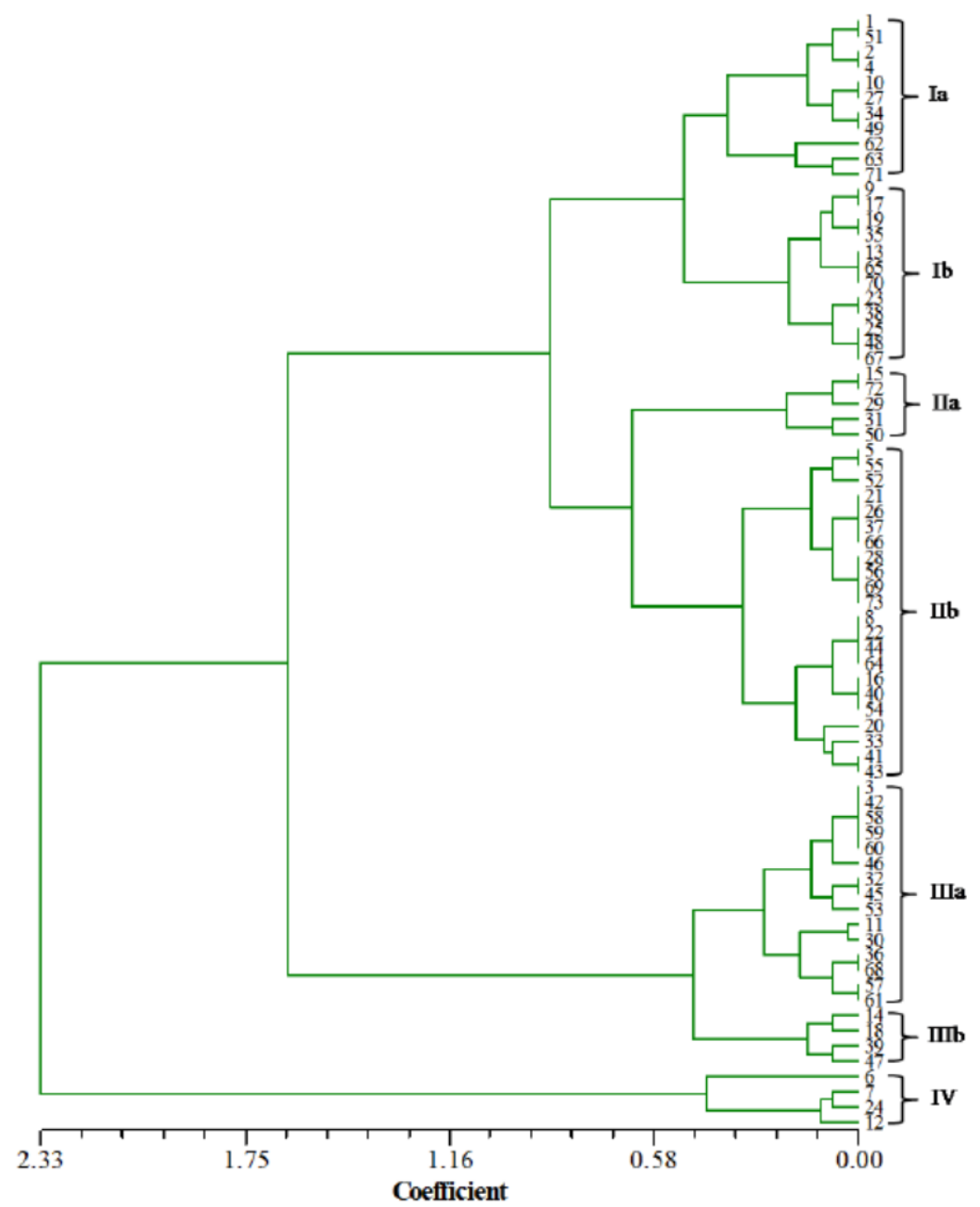

Fig 1. Dendrogram based on Jaccard's similarity coefficient of AUDPC after inoculation of rice germplasm accessions with Rhizoctonia solani. Most of the moderately resistant genotypes have been grouped in clusters I and II of the dendrogram.

Table 2. Allele size (bp) and polymorphism information content (PIC) of the SSR primers used in present study.

\begin{tabular}{lccccc}
\hline S. No. & Primer & PIC & $\begin{array}{c}\text { No. of alleles } \\
\text { amplified }\end{array}$ & $\begin{array}{c}\text { Approx. size of amplified product } \\
\text { (bp) }\end{array}$ & $\begin{array}{c}\text { Allele size (as amplified in } \\
\text { Tetep) }\end{array}$ \\
\hline 1. & Sbq1 & 0.00 & 1 & 210 (monomorphic) & 210 \\
2. & sbq11 & 0.421 & 2 & $150-160$ & 150 \\
3. & RM3691 & 0.260 & 2 & $130-160$ & 160 \\
4. & RM3428 & 0.236 & 2 & $140-170$ & 140 \\
5. & K39512 & 0.225 & 2 & $100-110$ & 220 \\
6. & RM536 & 0.335 & 2 & $210-220$ & 100 \\
7. & RM5481 & 0.00 & 1 & 100 (monomorphic) & 140 \\
8. & RM224 & 0.656 & 3 & $125-160$ & 165 \\
9. & RM306 & 0.516 & 3 & $150-210$ & 180 \\
10. & RM338 & 0.00 & 1 & 180 (monomorphic) & 150 \\
11. & RM257 & 0.315 & 2 & $110-150$ & 210 \\
12. & RM210 & 0.639 & 4 & $110-210$ & 180 \\
13. & RM202 & 0.362 & 2 & $160-180$ & 125 \\
14. & RM209 & 0.694 & 3 & $110-150$ & 175 \\
15. & RM336 & 0.743 & 4 & $140-210$ & 175 \\
16. & RM251 & 0.668 & 3 & $140-190$ & \\
\hline
\end{tabular}




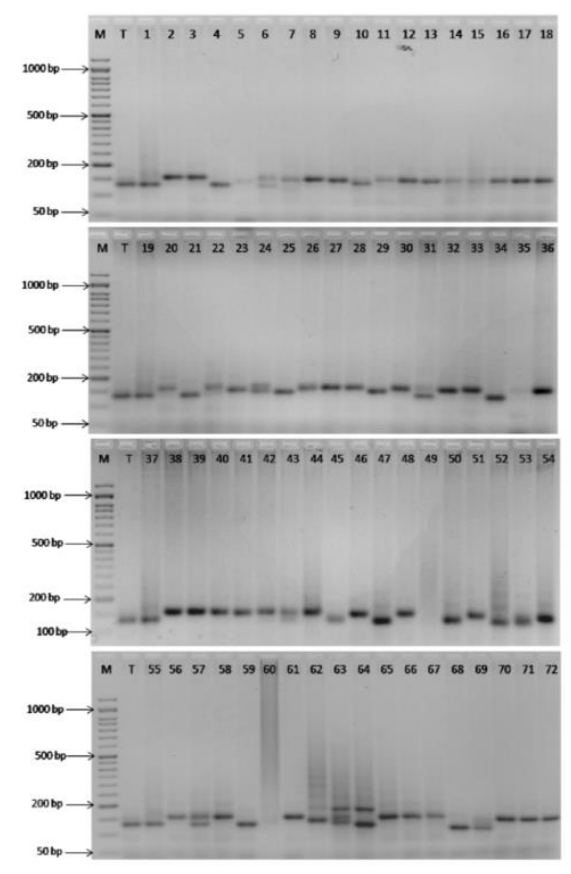

Fig 2. Gel images showing SSR banding profile obtained by primer RM224. Lane 1-72 represents the rice germplasm accessions; $\mathrm{M}=100 \mathrm{bp}$ DNA size marker and $\mathrm{T}=$ Tetep (used as resistant check to rice sheath blight disease). RM224 was one of the most informative primers on the basis of its high PIC value of 0.656 .

Table 3. Coefficient of dependent variable (AUDPC scores) in the stepwise multiple regression analysis for association with independent variables (SSR markers) towards sheath blight resistance in rice.

\begin{tabular}{|c|c|c|c|c|c|}
\hline Marker & Un-standardized coefficient $\beta$ & SE & $\begin{array}{l}\text { Standardized } \\
\text { coefficient } \beta\end{array}$ & T value & $P$ value \\
\hline RM257 150 & 0.451 & 0.134 & 0.359 & 3.377 & 0.001 \\
\hline RM251 $1_{175}$ & 0.315 & 0.118 & 0.284 & 2.667 & 0.010 \\
\hline
\end{tabular}

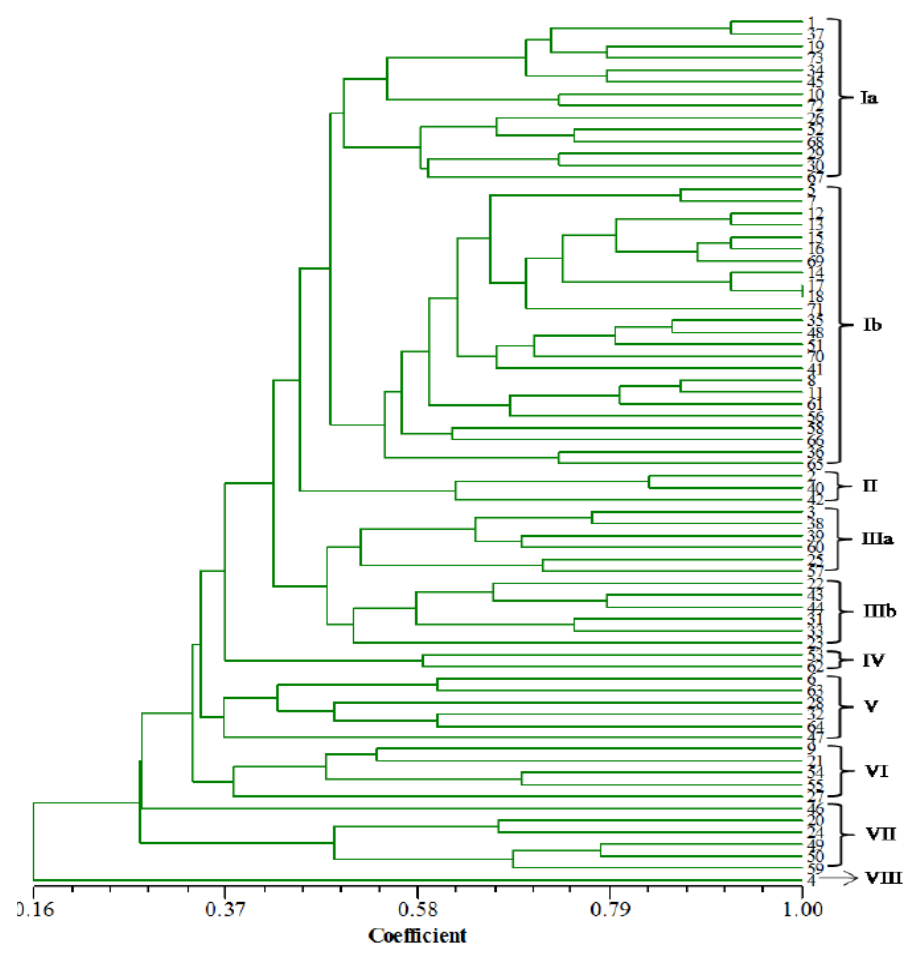

Fig 3. Dendrogram of germplasm accessions based on Jaccard's similarity coefficients of all the alleles amplified by 13 polymorphic SSR markers associated with sheath blight resistance in rice. 
Table 4. SSR markers associated with AUDPC of sheath blight resistance in rice as revealed by stepwise multiple regression analysis.

\begin{tabular}{lccccc}
\hline Marker & R2 & Adjusted R2 & R2 Change & F Change & P value of F change \\
RM257 150 & 0.127 & 0.114 & 0.127 & 10.29 & 0.002 \\
+ RM251 & 0.207 & 0.184 & 0.081 & 7.11 & 0.010 \\
\hline
\end{tabular}

+ denotes the inclusion of marker in the proceeding step in stepwise MRA

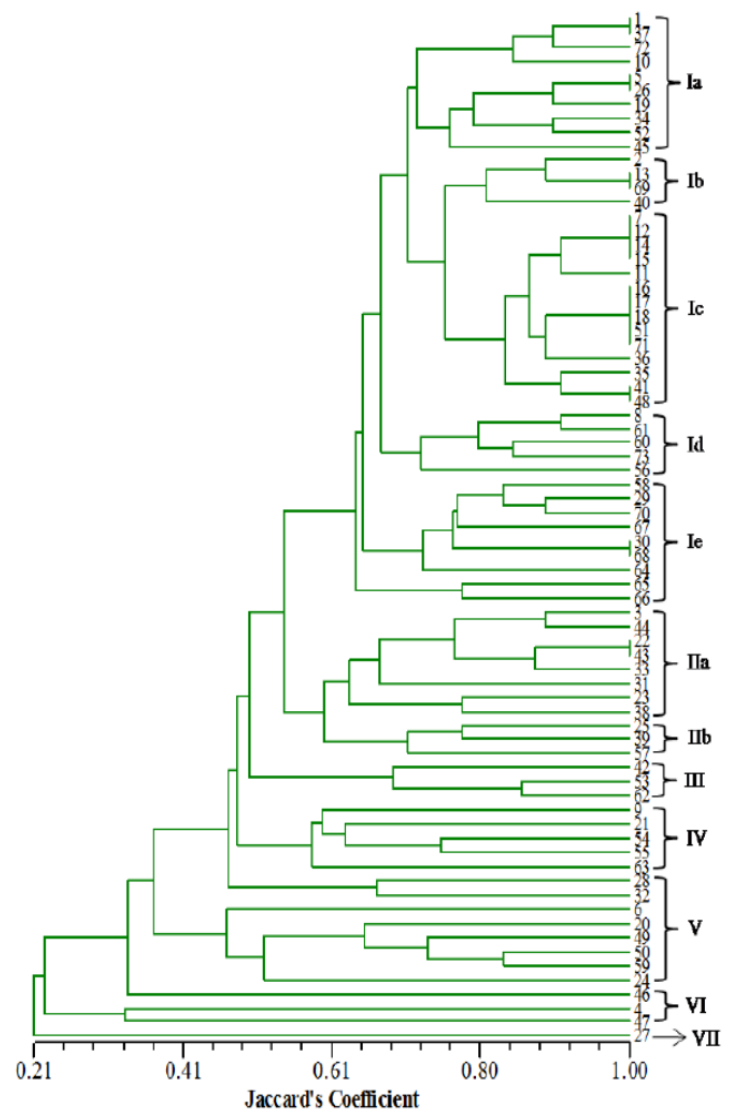

Fig 4. Dendrogram of germplasm accessions based on Jaccard's similarity coefficients of Tetep specific alleles amplified by 13 polymorphic SSR markers associated with sheath blight resistance in rice.

under the sub cluster Id. Cluster II consisted of 11 genotypes which were again divided into two sub clusters, i.e., IIa (8 genotypes) and IIb (3 genotypes). The clusters III, IV, V, VI and VII were not subdivided and consisted of genotypes three, five, eight, three and one, respectively.

\section{Multiple regression analysis}

Stepwise MRA was attempted to delineate the correlation of SSR markers (independent variables) with AUDPC (dependant variable) for sheath blight resistance in the rice germplasm accessions. The results of multiple regression analysis have been presented in Tables 3 and 4 .

\section{Discussion}

Absolute resistance to $R$. solani is not available in any of the rice germplasm accessions grown worldwide. A wide variation in susceptibility levels towards this pathogen is observed in different rice cultivars (Khush, 1977). The mechanism that provides quantitative resistance to $R$. solani in rice is still uncomprehended. However, some genotypes including the Indica rice line Tetep are well documented sources of quantitative resistance to sheath blight. The genotypes with higher AUDPC and PDI values are more susceptible to sheath blight than those with lower values. AUDPC and PDI values in the present study are quite similar to that observed by Chand et al. (2006), Taheri et al. (2007) and Adhipathi et al. (2013).

In order to determine the utility of molecular markers associated with QTLs for sheath blight resistance, the genotypes were screened with 16 SSR markers. These markers were reported to be linked to different SB resistant QTLs by Channamallikarjuna et al. (2010). Thirteen SSR markers were found to be polymorphic and three revealed the monomorphic banding pattern. An average of 2.6 fragments per locus was produced by primers showing polymorphic amplification. This value is lower than the average of 5.89 per microsatellite locus reported by Lapitan et al. (2007) and 4.23 alleles per locus reported by Ghneim et al. (2008) for Venezuelan rice cultivars. However, Seetharam et al. (2009) obtained 2.48 average number of polymorphic fragments per primer which is lower than that of present study.

PIC value is a reflection of allele diversity and frequency among genotypes. The PIC value observed in the present investigation ranged from 0.225 to 0.743 , which is 
comparable to previous estimates of microsatellite analysis in rice viz., 0.20-0.90 with an average of 0.56 (Jain et al., 2003), 0.477 to 0.782 with an average of 0.634 (Matin et al., 2012) and 0.51 to 0.90 with an average of 0.79 (Singh et al., 2013). RM336 was found to be the most appropriate marker to discriminate the rice genotypes owing to its highest PIC value of 0.743 .

The UPGMA dendrogram based on Jacquard's similarity coefficients of AUDPC grouped the genotypes into four main clusters, viz., Cluster I, II, III and IV. The cluster diagram obtained by all the 34 alleles, generated by 13 polymorphic SSR markers grouped the genotypes into eight major clusters. Based on the binary data generated by either presence or absence of an amplification fragment specific to resistant check Tetep, the genotypes were grouped broadly into seven clusters, viz., Cluster I, II, III, IV, V, VI and VII. In the previous studies, Tabkhkar et al. (2012) using SSR markers, grouped 48 rice genotypes in four main clusters and the dendrogram revealed that the landrace cultivars with good quality features were well separated from others. Kumar et al. (2014) grouped 134 rice genotypes into five clusters based on Euclidean cluster analysis.

The cophenetic correlation coefficient obtained in the present study was 0.84 for AUDPC. Its values for molecular data generated by all the alleles and Tetep specific alleles were found to be 0.79 and 0.81 , respectively. The values can be interpreted as good fit. These values are quite similar to that observed by Ming et al. (2010). A high cophenetic correlation means that the dendrogram has utility in clustering of genotypes and it does not arise due to the distortion in data. In the present study, UPGMA clustering based on molecular data and AUDPC are in close agreement with each other. Twenty five genotypes have been grouped as common in cluster I of dendrogram generated by all alleles, cluster I of dendrogram constructed by Tetep specific alleles, and clusters I and II of the AUDPC dendrogram. Most of the moderately resistant genotypes are common to these clusters of the three UPGMA based dendrograms.

Based on AUDPC values, the genotypes were categorized into four classes viz., resistant (R; AUDPC below 316.94), moderately resistant (MR; AUDPC >316.94 to 436.22), moderately susceptible (MS; AUDPC $>436.22$ to 565.0 ) and susceptible (S; AUDPC >565.0). This classification is in agreement with that of Biswas (2011). AUDPC value of 432.70 was recorded by Tetep in the present investigation which categorized it into the group of moderately resistant genotypes. Tetep was also used as resistant parent in the studies carried out by Channamallikarjuna et al. (2010).

The association between SSR markers (independent variables) and sheath blight resistance in terms of AUDPC (dependent variables) was estimated through stepwise multiple regression analysis (Tables 3 and 4). The marker RM257 150 revealed maximum (0.356) and highly significant $(t=3.377 ; P=0.001)$ correlation with AUDPC. The standardized beta coefficient was also very high (0.359) for this marker. Marker RM251 175 also showed a significantly high correlation (0.283) with AUDPC $(t=2.667 ; P=0.010)$. Marker RM257 150 explains $12.7 \%$ of total phenotypic variation and together with marker RM251 175 , it is able to explain $20.7 \%$ of the phenotypic variability. Thus, the two markers RM251 175 and RM257 ${ }_{150}$ can be taken as markers for association of low disease index (resistant to sheath blight) in rice. Sato et al., (2004) also reported two markers associated with sheath blight resistance in Tetep derived line (WSS2) of rice. Use of multiple regression analysis to identify molecular markers associated with resistance traits have been used in many plants species with great success (Virk et al., 1996 and
Kar et al., 2008). Ruan et al. (2009) estimated variability using ISSR markers in 52 accessions of sea buckthorn to find out markers associated with resistance to dried-shrink disease. Detection of markers associated with QTLs is the first step in marker assisted selection, whose success largely depends on the extent of genetic linkage between markers and concerned QTLs (Misztal, 2006 and Virk et al., 1996). The markers reported to be linked to rice SB resistance can be used in MAS breeding programs after validating them by testing their effectiveness.

\section{Materials and Methods}

\section{Site of the study}

The present study was carried out at the Department of Genetics and Plant Breeding, Institute of Agricultural Sciences, Banaras Hindu University, Varanasi (UP). The site of study is situated at $25^{\circ} 18^{\prime} \mathrm{N}$ latitude and $83^{\circ} 03^{\prime} \mathrm{E}$ longitude, at an elevation of $80.71 \mathrm{~m}$ above mean sea level.

\section{Plant material}

The research material consists of 73 morphologically diverse germplasm accessions of rice including one resistant check Tetep (Supplementary Table 1). These accessions were obtained from networking project involving National Research Centre on Plant Biotechnology (New Delhi), International Rice Research Institute (Philippines), Central Rice Research Institute (Cuttack, Odhisa) and Department of Genetics and Plant Breeding, Institute of Agricultural Sciences, BHU (Varanasi, India).

\section{Method of inoculation}

A virulent strain of $R$. solani 'MTCC-12227' was used for artificial inoculation of the test genotypes. The strain was grown on PDA medium at $28 \pm 3^{\circ} \mathrm{C}$. Five plants from each of the two replications were randomly selected and tagged before inoculation. The selected plants were inoculated at boot stage of the crop with a bit (approx. $0.25 \mathrm{mg}$ ) of fourdays-old immature sclerotium. For inoculation leaf sheath was opened carefully and inoculum was placed inside the sheath of tagged plants. Inoculation was done in the evening and inoculated plants were sprayed with few drops of sterilized water in the next morning.

\section{Disease screening in field condition}

The inoculated plants were regularly examined for appearance of symptoms starting from 48 hours of inoculation. Data on disease intensity was recorded after 20 days of inoculation (DAI) on three different dates at seven days interval (Kumar et al., 2008). The Area Under Disease Progress Curve (AUDPC) was calculated from disease severity (lesion length) by using the formula of Shaner and Finney (1977), Johnson and Wilcoxson (1982), and Campbell and Madden (1990).

$$
\text { AUDPC }=\sum_{\mathrm{i}=1}^{\mathrm{N}}\left[\left\{\left(\mathrm{Y}_{\mathrm{i}}+\mathrm{Y}_{(\mathrm{i}+1)}\right) / 2\right\} X\left(\mathrm{t}_{(\mathrm{i}+1)}-\mathrm{t}_{\mathrm{i}}\right)\right]
$$

Where, $Y_{i}=$ Disease level at the time $t_{i}$

$\left\{\mathrm{t}_{(\mathrm{i}+1)} \mathrm{t}_{\mathrm{i}}\right\}=$ Time in days between two disease scores

Rating scale of Sharma et al. (1990) was followed to calculate the Percent Disease Index (PDI).

$\mathrm{PDI}=[$ Sum of all ratings/ (No. of observations $\mathrm{x}$ maximum rating scale)] x 100 
Where $0=$ No infection; $1=$ Lesion limited to lower $20 \%$ of the height of the plant; $3=$ Lesion limited to lower $21-30 \%$ of the height of the plant; $5=$ Lesion limited to lower $31-45 \%$ of height of the plant; $7=$ Lesion limited to lower $46-65 \%$ of height of the plant; $9=$ Lesion more than $65 \%$ of the height of the plant.

\section{SSR analysis}

For molecular studies, DNA extraction was carried out from leaves of 15 days old seedlings according to CTAB method with slight modifications (Doyle and Doyle, 1987). DNA quality was evaluated by electrophoresis in $0.8 \%$ agarose gel and quantification was accomplished using spectrophotometer. For marker analysis, 16 SSR markers reported to be linked to various rice sheath blight resistance QTLs (Channamallikarjuna et al., 2010) were employed (Table 2). DNA amplification was carried out in $10 \mu \mathrm{l}$ reaction mixtures containing $2 \mu \mathrm{l}$ template DNA ( $5 \mathrm{ng}$ ), $5 \mu \mathrm{l}$ nano-pure water, 1 $\mu 1$ PCR buffer (10x), $0.48 \mu \mathrm{lMgCl}_{2}(50 \mathrm{mM}), 0.6 \mu \mathrm{l}$ dNTPs $(2 \mathrm{mM}), 0.4 \mu \mathrm{l}$ of each primer $(60 \mathrm{ng})$ and $0.12 \mu \mathrm{l}$ of Taq DNA Polymerase $(5 \mathrm{U} / \mu \mathrm{l})$. Polymerase chain reaction (PCR) was carried out in a thermal cycler (Eppendorf, USA) to the temperature cycle profile: initial denaturation at $94^{\circ} \mathrm{C}$ for 4 min, 40 cycles each of $1 \mathrm{~min}$ denaturation at $94^{\circ} \mathrm{C}$ followed $30 \mathrm{sec}$ annealing at $55^{\circ} \mathrm{C}$ to $65^{\circ} \mathrm{C}$ (depending on the primer employed) and 1 min extension at $72^{\circ} \mathrm{C}$, and finally 4 min at $72^{\circ} \mathrm{C}$ for the final extension.

The amplified products were subjected to electrophoresis in 2.5 percent agarose gel prepared in $1 \mathrm{x}$ TAE buffer and stained with ethidium bromide. The electrophoresis was carried out in $1 \mathrm{x}$ TAE buffer at constant voltage of $65 \mathrm{~V}$ for 3 hours. The gels were visualized and photographs taken using gel documentation instrument (BioRad). Clearly resolved and unambiguous bands for each primer were scored in the form of matrix as 1 (presence) and 0 (absence) in each genotype. The binary data matrix was then utilized to generate genetic similarity data among the 73 rice genotypes.

\section{Statistical analysis}

The AUDPC estimates and binary data matrix generated by polymorphic SSR markers were subjected to further analysis using NTSYS-pc version 2.02 (Rohlf, 1998). The SIMQUAL program was used to calculate the Jaccard's similarity coefficients. The resulting similarity matrix was used for unweighted pair group method with arithmetic averages (UPGMA) based dendrogram using the sequential agglomerative hierarchical nested cluster analysis (SAHN) module of NTSYS-pc. In order to estimate congruence among dendrograms, cophenetic matrices were computed and compared using Mantel test. Polymorphic information content (PIC) was estimated using the formula suggested by Nei (1973).

$\mathrm{PIC}=1-\sum \mathrm{x}^{2} \mathrm{k}$

Where, $x^{2} k$ represents the frequency of the $\mathrm{k}^{\text {th }}$ allele.

Association between SSR markers and rice SB resistance was estimated through stepwise multiple regression analysis (MRA) using the SPSS version 16.0. For stepwise multiple regression analysis, binary data generated by either presence or absence of an amplification fragment specific to resistant check Tetep in all the genotypes were used. The disease score in terms of AUDPC (quantitative trait) was treated as dependent variable and the thirteen polymorphic SSR markers were treated as independent variables. Selected markers were further tested with linear models for confirming the significance of $\beta$-statistics for each band identified by MRA.

\section{Conclusions}

Based on the cluster analysis of AUDPC and Tetep specific alleles, the genotypes IC383396 and IC426017 may be regarded as potentially resistant to sheath blight. Moreover, genotype IC281785 exhibited highest (793.33) and genotype IC346004 the lowest (217.78) area under disease progress curve, and thus may serve as prospective parents for developing mapping population for further genetic studies. It is to be worth mentioning that amplification of an allele specific to resistant check Tetep is not a sole criterion to confirm the resistance towards sheath blight. In order to use a particular molecular marker in MAS, association studies are essentially to be carried out with the trait of interest (sheath blight resistance in present case).

\section{Acknowledgement}

Authors thankfully acknowledge the Uttar Pradesh Council of Agricultural Research, Lucknow, India for financial support provided to accomplishing this work (Grant No. M21-132).

\section{References}

Adhipathi P, Singh V, Meena SC (2013) Virulence diversity of Rhizoctonia solani causing sheath blight disease in rice and its host pathogen interaction. The Bioscan. 8(3):949-952.

Biswas A (2011) Screening of rice varieties for sheath blight disease resistance in West Bengal, India. Env Ecol. 19:983-984.

Campbell CL, Madden LV (1990) Introduction to plant disease epidemiology. John Wiley and Sons, New York.

Chand R, Srivastava CP, Singh BD, Sarode SB (2006) Identification and characterization of slow rusting components in pea (Pisum sativum L.). Genet Res Crop Evol. 53:219-224.

Channamallikarjuna V, Sonah H, Prasad M, Rao GJN, Chand S, Upreti HC, Singh NK, Sharma TR (2010) Identification of major quantitative trait loci $q S B R 11-1$ for sheath blight resistance in rice. Mol Breeding. 25:155-166.

Dasgupta MK (1992) Rice sheath blight: the challenge continues. In: Singh, US, Mukhopadhyay AN, Kumar J, Chaube HS (ed) Plant diseases of international importance: diseases of cereals and pulses. Prentice Hall, Englewood Cliffs NJ, pp 130-150.

Dholakia BB, Ammiraju JSS, Santra DK, Singh H, Katti MV, Lagu MD, Tamhankar SA, Rao VS, Gupta VS, Dhaliwal HS, Ranjekar, PK (2001) Molecular marker analysis of protein content using PCR based markers in wheat. Biochem Genet. 39:325-338.

Dholakia BB, Ammiraju JSS, Singh H, Lagu MD, Roder MS, Rao VS, Dhaliwal HS, Ranjekar PK, Gupta VS, Web WE (2008) Molecular marker analysis of kernel size and shape in bread wheat. Plant Breed. 122:392-395.

Doyle JJ, Doyle JL (1987) A rapid DNA isolation procedure for small quantities of fresh leaf tissue. Phytochem Bull. 19:11-15.

Ghneim T, Posso D, Perez I, Torrealba G, Pieters AJ, Martinez CP, Tohme JM (2008) Assessment of genetic diversity in Venezuelan rice cultivars using simple sequence repeats markers. Electron $\mathrm{J}$ Biotechnol. 11(5):1-14. 
Han YP, Xing YZ, Chen ZX, Gu SL, Pan XB, Chen XL, Zhang QF (2002) Mapping QTL for horizontal resistance to sheath blight in an elite rice restorer line Minghui 63 . Acta Genet Sin. 29:565-570.

Hoeck JA, Fehr WR, Shoemaker RC, Welke GA, Johnson SL, Cianzio SR (2003) Molecular marker analysis of seed size in soybean. Crop Sci. 43:68-74.

Huang M, Xie FM, Chen LY, Zhao XQ, Jojee L, Madonna D (2010) Comparative analysis of genetic diversity and structure in rice using ILP and SSR markers. Rice Sci. 17(4):257-268.

Jain S, Mitchell SE, Jain RK, Kresovich S, McCouch SR (2003) DNA fingerprinting and phylogenetic analysis of Indian aromatic high quality rice germplasm using panels of fluorescent-labeled microsatellite markers. In: Khush GS, Brar DS, Hardy B (ed) Advance in Rice Genetics. IRRI, Philippine, pp 162-165.

Jia YL, Liu GJ, Costanzo S, Lee SH, Dai YT (2009) Current progress on genetic interactions of rice with rice blast and sheath blight fungi. Front Agric China. 3:231-239.

Johnson DA, Wilcoxson RD (1982) A table of areas under disease progress curves. Texas: Technical Bulletin. Texas Agricultural Experiment Station.

Kar PK, Srivastava PP, Awasthi AK, Urs SR (2008) Genetic variability and association of ISSR markers with some biochemical traits in mulberry (Morus spp.) genetic resources available in India. Tree Genet and Genom. 4:75-83.

Khush GS (1977) Disease and insect resistance in rice. Adv Agron. 29:268-341.

Kumar M, Singh V, Singh KN, Vikram P (2008) Morphological and virulence characterization of Rhizoctonia solani causing sheath blight of rice. Environ Ecol. 26:1158-1166.

Kumar N, Singh PK, Vaishampayan A, Saini R, Ram M, Singh A, Singh NK (2014) Genetic divergence analysis in rice under irrigated conditions. Indian J Plant Genet Resour. 27(3):246-250.

Kunihiro Y, Qian Q, Sato H, Teng S, Zeng DL, Fujimoto K, Zhu LH (2002) QTL analysis of sheath blight resistance in rice (Oryza sativa L.). Acta Genet Sin. 29:50-55.

Lapitan VC, Brar DS, Abe T, Redofia ED (2007) Assessment of genetic diversity of Philippine rice cultivars carrying good quality traits using SSR markers. Breed Sci. 57:263-270.

Liu G, Jia Y, Correa-Victoria FJ, Prado GA, Yeater KM, MaClung A, Correll JC (2009) Mapping quantitative trait loci responsible for resistance to sheath blight in rice. Phytopathology. 99:1078-1084.

Matin S, Ashrafuzzaman M, Islam MM, Sikdar SU, Zobayer N (2012) Molecular marker based (SSR) genetic diversity analysis in deep water rice germplasms of Bangladesh. Internat J Biosci. 2:64-72.

Maureira-Butler IJ, Udall JA, Osborn TC (2007) Analyses of a multi-parent population derived from two diverse alfalfa germplasm: testcross evaluations and phenotype-DNA associations. Theor Appl Genet. 115:859-867.

Misztal I (2006) Challenges of application of marker assisted selection- a review. Anim Sci Pap Rep. 24:5-10.

Nei M (1973) Analysis of gene diversity in subdivided populations. Proc Natl Acad Sci USA. 70:3321-3323.

Ou SH (1985) Rice Disease, 2nd edn. Common Wealth Mycological Institute, Kew, UK, pp 272.

Pan XB, Rush MC, Sha XY, Linscombe SD, Stetina SR, Oard, J (1999) Major gene, nonallelic sheath blight resistance from the rice varieties Jasmine 85 and Te Qing. Crop Sci. 39:338-346.
Pinson RMS, Capdevielle MF, Oard HJ (2005) Confirming QTLs and finding additional loci conditioning sheath blight in rice using recombinant inbred lines. Crop Sci. 45:503-510.

Rohlf FJ (1998) NTSYS-pc numerical taxonomy and multivariate analysis system. Version 2.02. Exeter Publications, Setauket, New York.

Ruan CJ, Li H, Mopper, S (2009) Characterization and identification of ISSR markers associated with resistance to dried-shrink disease in sea buckthorn. Mol Breed. 24:255-268.

Sato H, Ideta O, Audo I, Kunihiro Y, Hirabayashi H, Iwano M, Miyasaka A, Nemoto H, Imbe, T (2004) Mapping QTLs for sheath blight resistance in the rice line WSS2. Breed Sci. 54:265-271.

Seetharam K, Thirumeni S, Paramasivam K (2009) Estimation of genetic diversity in rice (Oryza sativa L.) genotypes using SSR markers and morphological characters. Afr J Biotech. 8(10):2050-2059.

Shalini KV, Manjunatha S, Lebrun P, Berger A, Baudouin L, Pirany N, Ranganath RM, Prasad, DT (2007) Identification of molecular markers associated with mite resistance in coconut (Cocos nucifera L.). Genome. 50:35-42.

Shaner G, Finney RE (1997) The effect of nitrogen fertilization on the expression of slow-mildewing resistance in Knox wheat. Phytopathogy. 67:1051-1056.

Sharma NR, Teng PS, Olivares FM (1990) Comparison of assessment methods for rice sheath blight disease. Philippines Phytopathology 26:20-24.

Singh A, Singh B, Panda K, Rai VP, Singh AK, Singh SP, Chouhan SK, Rai V, Singh PK, Singh NK (2013) Wild rices of eastern Indo-gangetic plains of India constitute two subpopulations harbouring rich genetic diversity. Plant Omics. 6(2):121-127.

Tabkhkar N, Rabiei B, Sabouri A (2012) Genetic diversity of rice cultivars by microsatellite markers tightly linked to cooking and eating quality. Aust J Crop Sci. 6(6):980-985.

Taheri P, Gnanamanickam S, Hofte M (2007) Characterization, genetic structure, and pathogenicity of Rhizoctonia spp associated with rice sheath diseases in India. Phytopathology. 97:373-383.

Vijayan K, Srivatsava PP, Nair CV, Awasthi AK, Tikader A, Sreenivasa B, Urs SR (2006) Molecular characterization and identification of markers associated with yield traits in mulberry using ISSR markers. Plant Breed. 125:298-301.

Virk PS, Ford-Lloyd BV, Jackson MT, Pooni HS, Clemeno TP, Newbury HJ (1996) Predicting quantitative variation within rice germplasm using molecular markers. Heredity. 76:296-304.

Wang D, Wei ZG, Yang CP, Liu GJ (2008) Analysis and identification of SCAR molecular markers associated with birch fiber length trait. J For Res. 19:288-292.

Wang Y, Pinson SRM, Fjellstrom RG, Tabien RE (2012) Phenotypic gain from introgression of two QTLs, qSB9-2 and qSB12-1, for rice sheath blight resistance. Mol Breed. 30:293-303.

Xu Q, Yuan XP, Yu HY, Wang YP, Tang SX, Wei XH (2011) Mapping quantitative trait loci for sheath blight resistance in rice using double haploid population. Plant Breed. 130:404-406.

Zheng A, Lin R, Zhang D, Qin P, Xu L, Ai P, Ding L, Wang Y, Chen Y, Liu Y, Sun Z, Feng H, Liang X, Fu R, Tang C, Li Q, Zhang J, Xie Z, Deng Q, Li S, Wang S, Zhu J, Wang L, Liu H, Li P (2013) The evolution and pathogenic mechanisms of the rice sheath blight pathogen. Nat Commun. 4:14-24. 